\title{
Pragmatic gains in the study abroad context: Learners' experiences and recognition of pragmatic routines
}

The present study investigates second language (L2) learners' pragmatic development during study abroad (SA) programs by focusing on the recognition of pragmatic routines, and how sociocultural adaptation and intensity of interaction influence pragmatic gains. It is a longitudinal investigation that employed a mixed-method approach. Thirty-one Brazilian students in their first semester of study in a US university completed a pretest and posttest version of a sociocultural adaptation questionnaire, a language contact survey, and a routine recognition test. Quantitative data were complemented with qualitative information from semi-structured interviews with 2 of the participants, who provided details about the nature of their adaptation experiences and the patterns of interaction they held during the sojourn. Findings revealed that the recognition of pragmatic routines significantly increased during a semester abroad, and that this development was influenced by both sociocultural adaptation and intensity of interaction, interaction being the main predictor of pragmatic gains. Results from this study emphasize the importance of SA programs for the acquisition of pragmatic routines, and suggest that learners' willingness to acculturate in the SA environment, and exposure to recurrent situations outside of the classroom are determinant aspects for routine recognition.

Keywords: L2 pragmatic development; interlanguage pragmatics; pragmatic routines; sociocultural adaptation; intensity of interaction; pragmatic awareness

\section{Introduction}

With globalization, the traditional view of second language (L2) learning as an approximation to native-like proficiency is changing to conceiving L2 learning as a tool to mediate across 
linguistic and cultural boundaries (Wilkinson, 2012). L2 learners are now required to be "intercultural speakers" (Byram, 2012), which implies that they need to be both pragmatically and interculturally competent. On the one hand, they should be able to use language accordingly to the norms of the given society, and to the norms of interaction with different interlocutors. On the other hand, they need to have certain attitudes, knowledge and skills to understand cultural differences and to engage in intercultural endeavors. Recent research (e.g. Taguchi, Xiao \& Li, 2016; Sykes, 2017; Taguchi \& Roever, 2017) points out that in order to account for pragmatic gains in the study abroad (SA) context, studies need to consider new trends that have gained importance in the present era of globalization, such as the interdependence of intercultural and pragmatic competences, areas that have traditionally belonged to different domains (Psychology and Linguistics respectively).

The interdependence of intercultural and pragmatic competences is addressed in this study by exploring the influence of sociocultural adaptation - an element of intercultural ability - on the recognition of pragmatic routines; that is, semi-fixed expressions used recurrently by native speakers (NSs) in specific situations (e.g. "for here or to go?" or "no, thanks, I'm full'). In addition, the study analyzes the role of intensity of interaction - that is, amount and nature of contact with L2 users -, as previous studies have highlighted its paramount role in L2 pragmatic acquisition (e.g. Bardovi-Harlig \& Bastos, 2011; Bella, 2011). Whilst it has been acknowledged that routine recognition highly depends on intensity of interaction in the L2 (e.g. Kecskes, 2000; Roever, 2012), a longitudinal investigation of the relationship between L2 exposure and gains in the recognition of routines still represents a research desideratum. This investigation fills in this research gap by exploring the influence of sociocultural adaptation and intensity of interaction on gains in recognition of pragmatic routines during a semester of SA. To address this purpose, the study accounts for both general patterns of pragmatic development and individual learners' trajectories through the employment of a mixed-methods approach. 


\section{Theoretical background}

\subsection{Pragmatic development in the study abroad context}

In the recent years, the field of Interlanguage Pragmatics (ILP) has seen a proliferation of longitudinal studies addressing the development of pragmatic competence over a period of time studying abroad (see Xiao, 2015a, for a review of longitudinal ILP studies). As different scholars have argued (e.g. Taguchi, 2015), developmental studies are particularly necessary in the ILP field. Given the non-linear and variable nature of L2 pragmatic development, the analysis of the processes rather than the outcomes of SA provides a more comprehensive understanding of the SA experience. Nowadays, there is substantial evidence of the benefits of participation in SA programs for the development of L2 pragmatic ability (Barron, 2003; Matsumura, 2003; Cohen \& Shively, 2007; Kinginger, 2008; Schauer, 2009; Bataller, 2010; Shively, 2011; Taguchi, 2008, 2011; Ren, 2015; Alcón-Soler, 2015, 2017; Alcón-Soler \& Sánchez-Hernández, 2017). In addition, it seems that pragmatic development is subject to the pragmatic feature under study, to contextual factors, and to learners' individual differences. Firstly, not all pragmatic features present the same degree of difficulty, with the development of some aspects (i.e. greetings and leave-takings) being faster than that of others (i.e. refusals and invitations) (Barron, 2003; Félix-Bradefer, 2004; Hassall, 2006). Secondly, main contextual factors that determine L2 pragmatic development are length of stay and intensity of interaction with L2 users, although scholars seem to agree that, when the two variables are compared, intensity of interaction plays a more significant role (Bardovi-Harlig \& Bastos, 2011; Bella, 2011). Thirdly, pragmatic development during SA is likely to vary across individual learners, and particularly across learners of different proficiency levels (e.g. Al-Gahtani \& Roever, 2012; see Xiao, 2015b, for a discussion of the effects of proficiency on L2 pragmatic development, and Sánchez-Hernández \& Alcón-Soler, forthcoming 2018, for a review of the influence of individual differences on L2 pragmatic development). 
Acknowledging the fact that pragmatic gains in the SA context are subject to the given pragmatic aspect, to contextual factors, and to individual differences, the present study analyzes the interdependence of these three constructs. More particularly, it explores the influence of the contextual factor of intensity of interaction, and the individual difference of sociocultural adaptation on the ability to recognize pragmatic routines. In what follows, previous literature on the recognition of pragmatic routines is reviewed, followed by previous research on the relationship between L2 pragmatic competence, intensity of interaction, and the wider notion of intercultural competence.

\subsection{Recognition of pragmatic routines}

Pragmatic routines ${ }^{1}$ are semi-fixed expressions used recurrently by members of a speech community in specific situations of everyday life. Examples of routines include "have a nice day" in service encounters, "help yourself" when offering food to someone, and "for here or to go?" when ordering food in the US. Indeed, pragmatic routines are culturally specific, and their meaning is bound to such particular situations that are frequently found in the SA context. It has been acknowledged that the use of pragmatic routines enhances L2 learners' oral fluency, bringing them closer to native-like production of the language (Weinert, 1995). Additionally, reliance on routines seems to help L2 learners gain confidence, as they feel that they are more clearly understood by NSs (Dechert, 1983). Within the SA context, the use of pragmatic routines helps L2 learners develop their interactional skills and communicate not only with NSs but also with other language users, thus allowing them to fit into the target language (TL) community to a greater extent (Wray, 2000; Roever, 2012)."

\footnotetext{
${ }^{1}$ Pragmatic routines have been discussed in ILP literature under a variety of labels, including conventional expressions (Bardovi-Harlig, 2008, 2009), situation-bound utterances (Kecskes, 2000, 2010), routine formulae (Roever, 2012), formulaic expressions (Taguchi, Li \& Xiao, 2013), and formulaic sequences (Dörnyei, Durow \& Zahran, 2004). Following a number of recent ILP studies (e.g. Barron, 2003, this issue; Taguchi, 2008, Taguchi \& Roever, 2017; Tajeddin, Alemi \& Pashmforoosh, 2017) this study adopts the term pragmatic routines an attempt to highlight the pragmatic nature of the linguistic feature.
} 
Different studies have pointed out that production and recognition of pragmatic routines represent different abilities (Bardovi-Harlig, 2008, 2009; Bardovi-Harlig \& Bastos, 2011; Alcón-Soler \& Sánchez-Hernández, 2017; Taguchi \& Roever, 2017). While production of routines is determined by learners' proficiency level and by opportunities for interaction, recognition mainly depends on exposure to the routines in context. An L2 learner may not initially recognize the meaning of a pragmatic routine, but through exposure and engagement in socialization practices they learn their meaning and use in context (Roever, 2012). Kesckes $(2000,2010)$ proposes that this process of learning the meaning of routines is a matter of cognitive ability. Since routine meanings are bound to given situations and to use by members of the speech community, students need first to learn about the sociopragmatic norms of use, to then make meaning-form connections. Such process of making meaning-form associations in routine recognition was illustrated by Bardovi-Harlig (2014), who found that students firstly acquired the form of the routine, and progressively learned to assign plausible meanings. The paramount role of exposure to the L2 context for the recognition of pragmatic routines has also been pointed out in a series of cross-sectional studies which have compared learners at different developmental stages. These studies have focused on various aspects of L2 exposure, including intensity of interaction with L2 users (Bardovi-Harlig \& Bastos, 2011), length of stay in the SA setting (Roever, 2005, 2012; Roever, Wang \& Brophy, 2014), and previous SA experience (Taguchi, 2011). These studies have also revealed that, although longer stays in the SA setting seem to correspond with higher routine recognition levels, what matters is contact with $L 2$ users in a variety of settings where routines are used.

While the above cross-sectional studies provide some insights into acquisitional patterns of routine recognition by different groups of L2 learners, longitudinal investigations are needed to illustrate how exposure to the TL during SA interacts with actual patterns of pragmatic change by the same group of students. Indeed, different scholars agree that longitudinal 
studies of L2 pragmatic development during SA allow for a more in-depth account of the learning experience (Barron, 2003; Taguchi, 2016). ${ }^{2}$ To our knowledge, longitudinal studies addressing pragmatic routines are still scarce, and, with the exception of Alcón-Soler and Sánchez-Hernández (2017), they have focused on production (Barron, 2003, this issue; Taguchi, Li \& Xiao, 2013; Osuka, 2017). Alcón-Soler and Sánchez-Hernández (2017) explored gains in the recognition and production of pragmatic routines by international students in their first semester of immersion in a US university, reporting higher gains in recognition than in production of routines, and an influence of proficiency and type of routine on both abilities. Students showed greater gains in the recognition of situational routines that is, routines whose meaning is bound to a particular situation - and lower gains in understanding functional routines - routines with a more literal meaning whose meaning can be inferred without contextual cues. Nevertheless, the question still remains as to whether factors such as sociocultural adaptation and intensity of interaction predict gains in routine recognition.

\subsection{L2 pragmatic development in relation to intercultural competence and intensity of interaction}

The relationship of L2 pragmatic development with intercultural competence and intensity of interaction has long been acknowledged in different theories of L2 pragmatic acquisition. In his Acculturation Model, Schumann (1978) proposed that the degree to which an individual acculturates to the TL society will determine their acquisition of an L2 in general and of L2 pragmatic competence in particular. According to Schumann, acculturation entails a set of aspects related to psychological (i.e. affective) and to sociocultural adaptation. ${ }^{3}$ Moreover, scholars drawing from the language socialization theory (Ochs, 1996; Ochs \& Schieffelin,

\footnotetext{
2 See Taguchi $(2008,2015,2016)$ for a discussion on the benefits of using longitudinal investigations in ILP. According to the author (2015: 6), "the strength of longitudinal studies using a mixed methods approach is their descriptive and explanatory power."

${ }^{3}$ Schmidt's (1983) case study of Wes, a Japanese immigrant in the US, was based on Schumann's Acculturation model.
} 
2008) put forward the idea that language and culture learning take place through social interaction. By means of observation and participation in social practices with members of the TL community, novices are gradually exposed to the new culture and acquire communicative resources that enhance their membership in the community ${ }^{4}$. More recently, drawing from dynamic-complex approaches to SLA, Taguchi (2012) proposed that L2 pragmatic development is a complex and non-linear process that, in addition to contextual factors, is largely shaped by learners' individual differences such as their personality, processing ability or proficiency. ${ }^{5}$ From this review of theoretical underpinnings, one may conclude that L2 pragmatic development is a variable learning process that is shaped by the interplay among context, culture(s), social interaction with L2 users, and by learners' individual differences.

Drawing from these assumptions, a great deal of ILP studies addressing L2 pragmatic learning in the SA context has accounted for the role of intensity of interaction in the L2 (e.g. Matsumura, 2008; Bardovi-Harlig \& Bastos, 2011; Taguchi et al., 2013). Nevertheless, very few ILP studies have focused on the variable of intercultural competence (exceptions include Taguchi, 2015; Sánchez-Hernández, 2018a), and even less have explored L2 pragmatic development in relation to both intensity of interaction and intercultural competence (with the exception of Shively \& Cohen, 2008; Taguchi et al., 2016).

Regarding intensity of interaction ${ }^{6}$, there is substantial empirical evidence that amount and nature of contact with L2 users influence the acquisition of pragmatic competence in the SA context (e.g. Matsumura, 2003; Taguchi 2008; Bardovi-Harlig \& Bastos 2011; Bella, 2011,

\footnotetext{
${ }^{4}$ Shively's (2011) study was based on the language socialization theory. It focused on the development of request behavior in service encounters in Spain by US students.

${ }^{5}$ Barron (2003)and Kinginger (2008) are examples of ILP studies based on complex, dynamic approaches to $L 2$ pragmatic development during SA.

${ }^{6}$ Also referred to as social contact (Taguchi, 2008; Taguchi et al., 2016), social interaction (Dewey, 2017), amount of interaction (Eslami \& Ahn, 2014) and amount of exposure (Matsumura, 2003). In the present study, we adopt the term intensity of interaction, which has been widely used in ILP research, in an attempt to account for both amount and nature of the interactions (e.g. Bardovi-Harlig \& Bastos, 2011; Bella, 2011, 2012; Félix-Brasdefer, 2013).
} 
2012; Félix-Brasdefer, 2013). Although overall findings point to the benefits for pragmatic development of higher amounts of interaction and in a variety of settings, studies have also showed the difficulty SA participants have in gaining access to the TL community, which is likely to result in limited opportunities for interaction and in small pragmatic gains (e.g. Freed, 1995; Wilkinson 1998). ILP studies addressing the role of intensity of interaction on L2 pragmatic gains have measured interaction qualitatively and quantitatively. Qualitative studies have mainly drawn from the language socialization theory to provide descriptive accounts of the amount and nature of the interactions SA participants hold during a sojourn (Siegal, 1994; lino, 1996; Ochs, 1996; Shively, 2011). Quantitative ones have commonly measured intensity of interaction through different versions of the Language Contact Profile (LCP) (Freed, Dewey, Segalowitz, \& Halter, 2004), an instrument that assesses the amount of time spent using the L2 in different situations (Matsumura, 2003; Taguchi 2008; BardoviHarlig \& Bastos 2011; Taguchi et al., 2013). Out of these studies, Bardovi-Harlig and Bastos (2011) focused on pragmatic routines. They explored the role of proficiency, intensity of interaction and length of stay on the recognition and production of routines SA participants in the US. Findings revealed an influence of interaction on both abilities, proficiency only affecting routine production, and length of stay not playing a significant role.

Nevertheless, most of the studies dealing with the relationship between intensity of interaction and L2 pragmatic competence have been cross-sectional, and very few have explored such relationship longitudinally (exceptions include Matsumura, 2003; Shively \& Cohen, 2008; Taguchi et al., 2013; Taguchi et al., 2016). According to Taguchi et al. (2016), this is an important aspect to consider as amount of contact may change during a sojourn, and therefore it is likely to influence pragmatic development to different extents. In this sense, Taguchi et al. (2013) focused on gains in the production of $L 2$ Chinese pragmatic routines, reporting that learners' proficiency level mediated the influence of perceived interaction on routine production. That is, changes in the amount of interaction only influenced pragmatic gains by lower-level students. 
As for intercultural competence, it involves "a complex of abilities needed to perform effectively and appropriately when interacting with others who are linguistically and culturally different from oneself" (Fantini, 2006: 12). The relationship between intercultural and pragmatic competences has been acknowledged by different scholars who recognize that engaging in intercultural communication enhances the ability to use language appropriately to the context (e.g. Sykes, 2017; Taguchi \& Roever, 2017). As Sykes (2017: 119) explains, "pragmatics is inherently the place where language and culture meet, and is encompassed in numerous approaches to operationalizing models of intercultural competence". Nevertheless, little empirical research has addressed the relationship between the two abilities, and the few available studies have revealed mixed and inconclusive findings.

Some have reported an effect of intercultural competence on L2 pragmatic acquisition (Schmidt, 1983; Rafieyan et al., 2015; Sánchez-Hernández, forthcoming 2018b). SánchezHernández (forthcoming 2018b), for instance, reported that positive gains in speech act production were determined by integration strategies and by academic pressure. However, Taguchi (2014) only found a partial relationship between sociocultural adaptation and pragmatic gains, since adaptation only influenced the appropriateness of speech act production, but not speech style. In addition to this, there is also evidence of no relationship between the two constructs (Shively \& Cohen, 2008).

These studies have drawn on different intercultural competence models traditionally studied in the field of Psychology, including the frameworks of Kelley \& Meyer's (1995) (Taguchi, 2015; Taguchi et al. 2016), Schumann's Acculturation theory (1978) (Schmidt, 1983; Sánchez-Hernández, 2018a), Bennett's (1993) model of intercultural sensitivity (Shively \& Cohen, 2008), and Berry's (1980) model of acculturation (Rafieyan et al., 2015). What all IC models share is that (1) intercultural competence entails a set of knowledge, skills, attitudes 
and personality traits, and that (2) it is a skill enhanced by a combination of firsthand experience of cultural diversity and critical reflection (Vande Berg, Paige \& Lou, 2012).

The present study focuses on one particular aspect of intercultural competence; that is, sociocultural adaptation. Sociocultural adaptation refers to the changes related to how an individual acquires cultural values and social skills, and is able to apply them in day-to-day situations (Ward \& Kennedy, 1999) ${ }^{7}$. Ward and Kennedy (1999) distinguished 2 subscales within sociocultural adaptation, namely behavioral adaptation - which involves the ability to manage everyday situations and interactions, - and cognitive adaptation - involving an understanding of the values and customs of the TL society. This aspect of intercultural competence is particularly suitable for the focus of the present study, given the situational nature of pragmatic routines ${ }^{8}$, which are likely to be learned with exposure to specific recurrent situations of the SA context. According to Masgoret and Ward (2006), sociocultural adaptation does not entail L2 learners having to adopt the TL values, but rather being aware of them to deal with daily situations in the new context effectively. To our knowledge, only Sánchez-Hernández (2018a) has focused on the relationship between sociocultural adaptation and L2 pragmatic development. Using a mixed-methods approach, the study explored the development of routine production by 87 international students of diverse nationalities in the US. Findings showed that that sociocultural adaptation, and more particularly behavioral adaptation, had a partial effect on pragmatic gains, due to the mediation of learners' background culture, which had a direct influence on routine production.

The relationship among intercultural competence, intensity of interaction and L2 pragmatic acquisition, to the best of our knowledge, has only been addressed in two quantitative

\footnotetext{
7 The concept of sociocultural adaptation was proposed by Ward and colleagues (e.g. Ward \& Kennedy, 1999; Ward, Bochner, \& Furnham, 2001)

8 See Alcón-Soler and Sánchez-Hernández (2017) for a discussion on the situational nature of pragmatic routines.
} 
studies: Shively and Cohen (2008), and Taguchi et al. (2016). These studies, however, have revealed mixed-findings. Shively and Cohen (2008) explored the development of requests and apologies in L2 Spanish by 67 US students spending one semester in Spain. Out of the different independent variables explored (i.e. learner's individual differences, intercultural competence and intensity of interaction), only 2 aspects of intensity of interaction correlated with pragmatic gains, namely speaking Spanish outside of class with NSs and other fluent speakers of Spanish, and speaking Spanish with the host family. The study revealed no significant correlation between intercultural competence (based on Bennet's, 1993 model $^{9}$ ) and pragmatic development. The authors hypothesized that students may have developed their overall intercultural ability but not their ability to deal with the situations presented in the pragmatic test. Focused on L2 Chinese, Taguchi et al. (2016) explored the effects of intercultural competence (based on Kelley \& Meyer, $1995^{10}$ ) and intensity of interaction on gains in speech act production by 109 US students spending one semester in China. Findings from their study revealed that learners improved the use of routines to produce requests, refusals, and compliment responses, and that this increase was directly predicted by intensity of interaction, and indirectly by intercultural competence - that is, intercultural competence only playing a role when combined with intensity of interaction.

From these two studies, we may conclude that intensity of interaction seems to be a main predictor of L2 pragmatic development, while there is not substantial evidence of the relationship between intercultural and pragmatic competences. Nevertheless, the two investigations have been limited to quantitative analyses. As proposed by recent approaches to L2 pragmatic development that are based on complex-dynamic models of SLA (Taguchi, 2012), the fact that the two longitudinal investigations do not include qualitative data to

\footnotetext{
${ }^{9}$ Bennet's (1983) Developmental Model of Intercultural Sensitivity (DMIS) proposes that acquiring intercultural competence is a process that consists of 6 phases that lead to increased sensitivity to cultural differences.

${ }^{10}$ Kelley and Meyers (1995) operationalized intercultural competence as a set of 4 personality traits that lead to adaptation to the SA setting: emotional resilience, flexibility/openness, perceptual acuity, and personal autonomy.
} 
complement quantitative results may prevent them from providing a complete picture of L2 pragmatic development. To address this concern, the present study explores the influence of intensity of interaction and sociocultural adaptation on pragmatic development employing a mixed-methods approach.

In summary, previous research has pointed out the potential of intensity of interaction and of sociocultural adaptation in predicting pragmatic gains, but they reveal three key research gaps. Firstly, findings on the relationship between intercultural competence and pragmatic competence are very scarce and inconclusive. Secondly, few studies have treated intensity of interaction and intercultural competence as time-varying variables in relation to pragmatic competence. Thirdly, with the exception of Alcón-Soler and Sánchez-Hernández (2017), no previous study has explored gains in the recognition of pragmatic routines during SA. The present study fills in these research gaps by exploring the influence of sociocultural adaptation and intensity of interaction on the development of routine recognition in the SA context. To this end, the following research questions were formulated:

1. Does a semester-long SA program afford gains in the recognition of pragmatic routines?

2. To what extent, if any, do sociocultural adaptation and intensity of interaction influence gains in the recognition of pragmatic routines?

\section{Method}

The current study is a longitudinal investigation that employed a mixed-method approach in which qualitative data were used to further our understanding of the quantitative results. The combination of quantitative and qualitative research components allowed documenting pragmatic gains over time by exploring the factors that affect those gains (see Alcón \& Safont, 2018, for the benefits of using mixed-methods in longitudinal ILP research). 


\subsection{Participants}

The participants were 31 Brazilian students in their first semester of study at a US Midwest University. The sample consisted of 19 males and 13 females, and their age ranged from 19 to 23 , the average being 21 . In addition, 21 of them were monolingual Portuguese speakers, while 10 of them reported having additional knowledge of Spanish. None of the participants had previous experience in the US, and therefore the SA program constituted their first exposure to the TL sociocultural context. Moreover, the participants were enrolled in the same SA program, which aimed at enhancing their linguistic skills, and therefore the sample was homogeneous in terms of intended length of stay and living situation. All the students lived in the same block of apartments, and shared flats with other Brazilian students $(n=11)$, or with students of other nationalities $(n=20)$. The program consisted of a scholarship awarded by the Brazilian government on the basis of performance in a Test of English as a Foreign Language (TOEFL) exam at their home country. Hence, the sample of participants did not include beginner-level students, only intermediate-level learners of English $(n=19)$ and advanced ones $(n=12)$. For the grant awardees, the program covered travel and accommodation expenses for the students to spend one year of study at a US university, with the requirement of retaking and passing the TOEFL test at the end of the first semester. ${ }^{11}$

During the semester, learners had different amounts of English as a Second Language (ESL) instruction, although none of the ESL courses included pragmatic competence in their curriculum. More particularly, intermediate students were required to take part-time ESL classes (i.e. 4 hours per week), and advanced learners had to take content classes with NSs, and could voluntarily attend ESL classes.

11 To pass the TOEFL test they needed to achieve 550 points in the paper format of the exam. 
Additionally, a subset of eight students voluntarily participated as informants for the qualitative analysis by providing details of their SA experiences in semi-structured interviews with the main researcher. In this paper we report the case of two of the participants: Tim and Jeff, who were chosen on the basis of maximum sampling variation. Out of all the participants initially interviewed, Tim (a 23 year-old male) was the one that showed the highest gains in the recognition of routines, while Jeff (a 20-year old male) showed the lowest gains.

\subsection{Instruments}

The quantitative instruments consisted of a Vocabulary Knowledge Scale (VKS), a Sociocultural Adaptation Scale (SCAS), and a language contact survey at the beginning and at the end of the SA program. This information was complemented with qualitative data obtained through semi-structured interviews to two participants.

\subsubsection{Vocabulary Knowledge Scale (VKS)}

In order to collect data on the participants' recognition of pragmatic routines, a modified version of the multilevel Vocabulary Knowledge Scale (VKS, Wesche \& Paribakht 1996) was used. This test aimed to identify both self-perceived and demonstrated knowledge of 15 pragmatic routines, which were selected from previous studies on routine recognition (Roever, 2005; Bardovi-Harlig, 2008, 2009). The instrument has previously been used in ILP in a series of studies by Bardovi-Harlig $(2008,2009,2014)$ that also explored the recognition of pragmatic routines. In the present study, the original test was modified by reducing the possible answers from 5 to 3 to simplify and make more consistent the statistical analysis of the data. Example 1 shows one of the items in the test: 
(1) Instructions: Circle the letter a), b) or c) of the most appropriate option for each expression according to whether you have never seen or heard the expression, you have seen or heard it but do not remember what it means or you know the expression and are able to explain, translate or provide a synonym for it.

1. I gotta go

a) I don't remember seeing or hearing this expression before.

b) I have seen or heard this expression before but I don't know what it means.

c) I know this expression. It means

(translation, synonym or explanation)

The routines were presented in a decontextualized manner so as to assess whether the participants' were able to assign plausible meanings to the routines without contextual cues. As seen in the example, students have to draw from their sociopragmatic knowledge to provide a synonym, example or an explanation that demonstrates their ability to recognize the expression in context.

The instrument was pilot tested with 92 NSs. All the NSs (that is, 100\%) reported knowing the expressions (option $c$ in the VKS), although different definitions, examples and synonyms were provided. To determine the plausible meaning associated with each routine, we established a cut-off point of NSs agreement at $75 \%$. In other words, only meanings that were elicited by at least $75 \%$ of the NS sample were considered plausible. The cut-off point served as an indicator of validity of the instrument by showing NS agreement and it was also used to code the meaning of the presented pragmatic routines. After the cut-off point analysis, a final list of fifteen routines was established (see Table 1).

Finally, in order to avoid familiarity with the instruments in the posttest, two versions of the VKS were designed by modifying the order of the items presented.

\subsubsection{Sociocultural Adaptation Scale (SCAS)}


The SCAS (Ward \& Kennedy, 1999) was used to measure the participants' sociocultural adaptation in the US in terms of both behavioral and cognitive adaptation. It is a five-point Likert-scale in which students are asked to rate from 1 (= very difficult) to 5 (= no difficulty) their level of adaptation in 29 items. The original scale includes 41 items, but it is adaptable to particular local contexts by reducing it to 29 items (Ward \& Kennedy, 1999). These items include 7 cognitive aspects such as "seeing things from an American point of view" and "understanding the American political system", and 21 behavioral situations that include specific adaptation scenarios such as "finding food you enjoy", "getting used to the pace of life" and "making friends," and also aspects related to communication, such as "making yourself understood" and "understanding jokes and humor". In the present version, rating scores were reversed from the original scale so that higher scores correspond with a positive adaptation.

Reliability, internal consistency and validity of the SCAS were initially analyzed and corroborated by Ward and Kennedy (1999). They designed the scale by testing it across a wide range of culturally diverse groups of sojourning students and adults. In this study, Cronbach alphas were calculated for the overall instrument scale and for behavioral adaptation and cognitive adaptation subscales, the three ratios indicating a strong reliability ( $\alpha=0.937$ for overall sociocultural adaptation, $\alpha=0.910$ for behavioral adaptation, and $\alpha=$ 0.989 for cognitive adaptation).

\subsubsection{The Language Contact Survey}

The intensity of interaction questionnaire used in this study was an adapted version of the Language Contact Profile (LCP) developed by Freed et al. (2004). The purpose of the language contact survey was to assess the amount of contact in English in different contexts (e.g. the classroom, with friends, with strangers). The instrument used consisted of a preliminary question about living situation, followed by 8 situations in which participants were 
asked to indicate how many days per week and how many hours per day they spent using the L2 in different scenarios.

Freed et al.'s (2004) version of the LCP was modified in the present study by reducing the number of situations presented by (see Appendix). This adaptation was carried out for two purposes: to meet the purpose of our analysis (i.e. to explore the contexts in which the L2 is used), and to address some of the major limitations of the original instrument (see Fernández \& Tapia, 2016). Firstly, since we wanted to assess the amount and nature of interactions in daily situations that involved L2 use by the given speech community, amount of time spent writing and reading in the $\mathrm{L} 2$ were disregarded. Secondly, to avoid ambiguity in the items (Fernández \& Tapia, 2016), we only included those situations that illustrate the context in which the interactions take place (e.g. with service personnel), disregarding items about the purpose of the interaction (e.g. to talk about clarity of classroom-related work). Example 2 shows one of the items in the modified LCP.

(2) Instructions: Please respond to the questions below by circling the appropriate numbers.

On average, how much time do you spend speaking in English to your classmates?

$\begin{array}{lllllllllll}\text { Typically, how many days per week? } & 0 & 1 & 2 & 3 & 4 & 5 & 6 & 7\end{array}$

On those days, how many hours per day? $\quad 0-1 \quad 1-2 \quad 2-3 \quad 3-4 \quad 4-5 \quad$ more than 5

Fernández and Tapia (2016) emphasized the importance of adding a qualitative dimension to complement self-reported answers of the LCP. In our study, semi-structured interviews to a subsample of participants were conducted for such purpose.

\subsubsection{Semi-structured interviews}

A subset of 2 informants participated in semi-structured interviews at the beginning and at the end of the semester. The interviews aimed at eliciting reasons for individual trajectories 
of pragmatic learning, of adaptation development, and of patterns of interaction. The interviews were conducted in English, had a duration of 30 to 40 minutes, and were audio recorded in the principal researcher's office. Moreover, they were semi-structured so as to include flexibility in the pre-selected issues (i.e. aspects related to sociocultural adaptation, to amount and nature of interactions, and to awareness of knowledge of pragmatic routines).

\subsection{Data collection and analysis}

Employing a pretest/posttest design, the process of collecting the data took one semester. At the beginning of the semester, newly arrived international students were asked for participation during regular ESL lessons. The instruments were administered in paper format during face-to-face sessions. Pretests were completed on the second week of the semester, and posttests two weeks before the end of the semester. Additionally, upon completion of the pretest, students were asked to voluntarily participate in interviews, which took place the day after completion of the pretest instruments, and the day after administration of the posttests.

To code recognition of routines, each response in the VKS test received a point value and, for each participant, average scores were calculated on a scale from 0 to 2 . Zero points were given to answering option a) "I don't remember seeing or hearing this expression before". One point corresponded to two possibilities: option b) "I have seen or heard this expression before but I don't know what it means", and option c) "I know this expression. It means..." plus a non plausible meaning. Two points were assigned to the response "I know this expression. It means" followed by a plausible meaning. Before data coding, one of the authors and a recruited scholar practiced coding together on data from a pilot study to confirm consistency. They independently coded $20 \%$ of the study data, the agreement rate being $91 \%(r=0.91)$. 
Normality of the data was analysed through a series of Shapiro-Wilk's tests $(p>.05)$, which indicated that the data was normally distributed (Skewness and Kurtosis were between -1 and 1), and therefore parametric tests were used. To answer RQ1, gains in pragmatic awareness were calculated through a series of paired-samples t-tests. To answer RQ2, ttests were used for a first analysis of sociocultural adaptation and interaction gains, and a second analysis of the influence of these two variables on pragmatic development was conducted through regression analyses.

Moreover, to analyze the qualitative data, the content of the semi-structured interviews was explored by identifying issues that determined positive or negative development of sociocultural adaptation (e.g. development of social networks; attitude towards the US culture; academic adaptation; main adaptation difficulties; adaptation aspects they value) and of intensity of interaction (e.g. opportunities for interaction; amount of NSs with whom they regularly interact; efforts to improve their interaction).

\section{Results}

\subsection{Quantitative findings: general patterns}

The first research question of the study (RQ1) asked whether the SA context afforded gains in the recognition of pragmatic routines. Results from a paired-samples t-test indicated that the difference between pretest recognition scores $(M=17.58 ; S D=3.92 ; \operatorname{Min}=6 ; \operatorname{Max}=24)$ and posttest ones $(M=20.03 ; S D=3.26 ; \operatorname{Min}=10 ; \operatorname{Max}=25)$ was statistically significant $(M$ $=2.45 ; S D=3.32 ; t=-4.105 ; p=.00)$, the effect size being medium-large $(d=0.74)$. This finding indicates that the first semester of immersion in the SA context afforded gains in the recognition of pragmatic routines. 
Nevertheless, not all routines presented the same degree of difficulty for learners to recognize. Table 1 illustrates gain ratios in each of the pragmatic routine, organized in a descendent order from larger gain scores to smaller ones.

Table 1. Recognition of pragmatic routines

\begin{tabular}{lllll}
\hline & Pretest & Posttest & \multicolumn{2}{c}{ Gains } \\
Pragmatic routine & Score & Score & Score & $\%$ \\
\hline That works for me & 1.06 & 1.55 & 0.48 & 12.1 \\
Do you want to come to my place? & 1.48 & 1.81 & 0.32 & 8.06 \\
Can I get you anything else? & 1.35 & 1.65 & 0.30 & 7.3 \\
I was wondering... & 1 & 1.23 & 0.23 & 5.65 \\
My bad & 1.39 & 1.61 & 0.23 & 5.65 \\
Do you think you could make it? & 0.81 & 1.03 & 0.23 & 5.65 \\
Would you mind...? & 1.03 & 1.26 & 0.23 & 5.65 \\
I gotta go & 1.61 & 1.77 & 0.16 & 4.03 \\
Thanks for your time & 1.74 & 1.90 & 0.16 & 4.03 \\
Can I get a ride? & 0.92 & 1.03 & 0.13 & 3.25 \\
Could you do me a favor? & 1.81 & 1.94 & 0.13 & 3.25 \\
Thanks for coming & 1.71 & 1.81 & 0.10 & 2.42 \\
No problem & 1.88 & 1.98 & 0.10 & 2.42 \\
Help yourself & 0.94 & 0.94 & 0.00 & 0 \\
Do you have the time? & 1.65 & 1.55 & -0.10 & -2.42 \\
\hline
\end{tabular}

As we may observe in Table 1, gain scores ranged from $0.48(12.1 \%)$ in the routine "That works for me" to $-0.10(-2.42 \%)$ in "Do you have the time?", the average being $0.18(5 \%)$. On the one hand, students experienced the highest gains in the routines "That works for me", "'Do you want to come to my place $(0.32 ; 8.06 \%)$ and "can I get you anything else" $(0.30$; $7.3 \%)$. On the other hand, they showed the smallest gains in "Help yourself" $(0 ; 0 \%)$, "no problem" $(0.10 ; 2.42 \%)$ and "Thanks for coming" $(0.10 ; 2.42 \%)$. "Do you have the time?" was the only routine where students decreased their recognition score. This suggests that the 
students may encounter certain situations frequently enough to learn the prototypical meaning of the routine used, while other situations may not be that common. In the case of "Do you have the time?", one may hypothesize that the situation of having someone in the street ask a student about the time may not as frequent in today's era of technology, where people are likely to carry a cell phone which they use as a watch.

To shed more light on the reported recognition gains, we explored the participants' answers to the VKS in terms of the amount of responses on each of the VKS answers. Table 2 displays information on pretest, posttest, and differences (which indicates gains), expressed in number of participants $(\mathrm{N}=31)$ and in percentages.

Table 2. Descriptive statistics on answers to the VKS

\begin{tabular}{lcccccc}
\hline & \multicolumn{2}{c}{ Pretest } & \multicolumn{2}{c}{ Posttest } & \multicolumn{2}{c}{ Difference } \\
\cline { 2 - 7 } Answers in the VKS & $\mathbf{N}$ & $\%$ & $\mathbf{N}$ & $\%$ & $\mathbf{N}$ & $\%$ \\
\hline $\begin{array}{l}\text { c) Recognition+ } \\
\text { plausible meaning }\end{array}$ & 158 & 39.2 & 244 & 60.54 & 86 & 21.34 \\
\hline $\begin{array}{l}\text { c) Recognition + non- } \\
\text { plausible meaning }\end{array}$ & 53 & 13.15 & 92 & 22.83 & 39 & 9.67 \\
\hline b) Partial recognition & & & & & & \\
\hline a) No recognition & 137 & 33.99 & 49 & 12.16 & -88 & -21.83 \\
\hline
\end{tabular}

As it can be observed in Table 2, students improved their recognition of pragmatic routines in terms of producing more plausible meanings and reporting recognition of more routines, although the meaning was not always plausible. In contrast, they decreased their answers to options "a) I don't remember seeing or hearing this expression before" and "b) I have seen or heard this expression before but I don't know what it means." Moreover, the routines that most non-plausible meanings elicited were "That works for me" (e.g. "for example, John work to other people"), "Do you think you could make it" (e.g. can you do it for me?"), "my bad" (e.g. "where people sleep"), and "help yourself"(e.g. "take care of yourself"). 
Examples (3) and (4) illustrate these findings. Example (3) includes answers by one of the participants in the pretest and the posttest to the recognition of "help yourself", while Example (4) refers to the same participants' answers in the routine "do you think you could make it?". As we can see in the examples, the SA experience allowed the participant to acquire the necessary sociopragmatic knowledge to understand the plausible meanings of the routines, instead of the literal and non-plausible meaning that could be inferred without knowing how this expression is used in the given speech community.

(3) Help yourself

Pretest: c) I know this expression. It means: Do something for your own good

Posttest: c) I know this expression. It means: Take the food you want

(4) Do you think you could make it?

Pretest: c) I know this expression. It means: Are you able to do this?

Posttest: c) I know this expression. It means: Can you go to the event?

The second research question (RQ2) of the study examined whether sociocultural adaptation and intensity of interaction influenced the above-reported gains in the recognition of pragmatic routines. A first analysis concerned the development of sociocultural adaptation and intensity of interaction. Table 3 shows the descriptive statistics on gains in overall sociocultural adaptation, and in the two subscales: behavioral and cognitive adaptation.

Table 3. Sociocultural, behavioral and cognitive adaptation

\begin{tabular}{|c|c|c|c|c|c|c|}
\hline & \multicolumn{2}{|c|}{ Time 1} & \multirow{2}{*}{$\begin{array}{l}\text { Time } 2 \\
M\end{array}$} & \multicolumn{3}{|c|}{ Difference } \\
\hline & $M$ & $S D$ & & $S D$ & Score & $\%$ \\
\hline Sociocultural adaptation & 3.66 & 0.43 & 4.16 & 0.27 & $0.51^{*}$ & 12.75 \\
\hline - Behavioral & 3.67 & 0.44 & 4.15 & 0.30 & $0.47^{*}$ & 11.75 \\
\hline - Cognitive & 3.60 & 0.52 & 4.22 & 0.26 & $0.61^{*}$ & 15.25 \\
\hline
\end{tabular}


Results from a series of $t$-tests indicated that the participants significantly improved their overall sociocultural adaptation $[t(31)=6.8 ; p=.000 ; d=0.407]$, their behavioral one $[t(31)=$ $6.5 ; p=.000 ; d=0.355]$, and their cognitive one $[t(31)=6.22 ; p=.000 ; d=0.491]$, the effect size being medium. Additionally, we conducted a correlation test to determine whether behavioral and cognitive adaptation were associated with each other. The analysis indicated a positive association between behavioral and cognitive gains $[r(31)=.724 ; p=.000]$, implying that those students who improved their behavioral adaptation (e.g. going shopping) were likely to improve their cognitive adaptation too (e.g. having an American perspective on the culture), and vice versa. In particular, one may observe in Table 3 that the average difference between pre- and posttest was higher for cognitive adaptation (a 15.25\% increase) than for behavioral one (11.75\% of increase), suggesting that the SA context particularly enhanced the ability to understand the values and customs of the TL society. It should also be noted that not all situations presented the same degree of difficulty for students to acculturate. Students showed the highest gains in the cognitive situation "understanding cultural differences" and the behavioral one "making yourself understood", while they reported negative gains in two behavioral aspects, "finding food that you enjoy" and "dealing with the climate."

In a similar vein, Table 4 illustrates gains in overall intensity of interaction and in the 8 different situations included in the LCP. Mean ratios indicate average of hours per week spent in each communicative scenario.

Table 4. Intensity of interaction

\begin{tabular}{lllllll}
\hline & \multicolumn{2}{c}{ Time 1 } & Time 2 & \multicolumn{3}{c}{ Difference } \\
& $M$ & SD & $M$ & SD & Score & $\%$ \\
\hline Overall interaction & 69.06 & 24.92 & 83.67 & 32.81 & $14.61^{*}$ & 5.54 \\
- Speaking with NSs & 10.42 & 8.01 & 13.64 & 11.38 & 3.23 & 9.22 \\
- Speaking with instructor & 16.64 & 5.53 & 17.32 & 7.91 & 0.67 & 1.93 \\
- Speaking with classmates & 16 & 6.30 & 17.26 & 5.53 & 1.26 & 3.59 \\
\hline
\end{tabular}




\begin{tabular}{lllllll}
\hline - Speaking with strangers & 8.74 & 5.67 & 8.09 & 5.03 & -0.64 & -1.84 \\
- Speaking with roommates/friends & 4.87 & 4.89 & 6.77 & 9.00 & 1.90 & 5.44 \\
- Speaking with service personnel & 4.35 & 3.53 & 4.29 & 3.61 & -0.06 & -0.18 \\
- Listening to conversations & 16.26 & 9.64 & 19.58 & 11.46 & $3.32^{*}$ & 9.49 \\
- Watching TV/videos & 10.97 & 8.45 & 16.80 & 9.63 & $5.84^{*}$ & 16.68 \\
\hline
\end{tabular}

${ }^{\star} p<.05$ (paired-samples T-test).

As it can be observed in Table 4, the participants showed statistically significant positive gains in overall intensity of interaction, the effect size being medium $(t(31)=2.12, p=.043, d$ $=0.36$ ) (see Table 4). Nevertheless, a closer look at gains in each situation only revealed statistically significant gains in 3 of the situations, that is, speaking with NSs $(t(31)=2.39, p$ $=.051, d=0.23)$, listening to conversations $(t(31)=2.66, p=.012, d=0.37)$, and watching TV/videos $(t(31)=4.64, p=.000, d=0.45)$, the largest gains being in watching TV/videos (16.68\% of increase, compared with the $9.22 \%$ and $9.49 \%$ in the other two aspects).

To explore the influence of sociocultural adaptation and intensity of interaction on the recognition of pragmatic routines, a series of linear multiple regression analyses were conducted with routine recognition scores as the dependent variable. Table 5 displays the results from such analyses by including beta scores, $p$-values and effect sizes.

Table 5. Regression analyses on the influence of sociocultural adaptation on gains in the recognition of pragmatic routines.

\begin{tabular}{llll}
\hline & $\boldsymbol{\beta}$ & Sig. & $\boldsymbol{d}$ \\
\hline Overall sociocultural adaptation & .368 & .045 & .105 \\
- Behavioral adaptation & .338 & .067 & \\
- Cognitive adaptation & .375 & .041 & \\
\hline
\end{tabular}

A first analysis was calculated with 3 independent variables, namely gains in overall sociocultural adaptation, in behavioral and in cognitive adaptation (see Table 5). Results from the regression analysis revealed that overall sociocultural adaptation influenced the 
students' development of routine recognition $(\beta=.368 ; p=.045)$. Moreover, the effect size of the influence was medium, since the predictor variable, in this case sociocultural adjustment, accounts for the $10 \%$ of the variance of the dependent variable, namely recognition gains (adjusted $\left.R^{2}=.105\right)$. In fact, both behavioral adaptation $(\beta=.338 ; p=$ $.067)$ and cognitive adaptation $(\beta=.375 ; p=.041)$ significantly predicted pragmatic gains.

As for the influence of intensity of interaction on pragmatic development, Table 6 , which illustrates results from a linear regression analysis, shows that overall gains in amount of interaction significantly influenced development of recognition of pragmatic routines $(\beta=$ $\left..404 ; p=.024 ; R^{2}=.163\right)$. A second regression analysis focused on the three situations where students significantly increased their interaction; that is, speaking with NSs, listening to conversations and watching TV/videos, revealing that two of them, speaking with NSs ( $\beta$ $\left.=.344 ; p=.05 ; R^{2}=.18\right)$ and listening to conversations $\left(\beta=.299 ; p=.09 ; R^{2}=.15\right)$, played a significant role. This finding suggests that those students who increased their amount of interaction with L2 users were also likely to improve their recognition of routines. More particularly, pragmatic recognition was associated with increased speaking with NSs and with increased time spent listening to conversations.

Table 6. Regression analyses on the influence of intensity of interaction on gains in the recognition of pragmatic routines.

\begin{tabular}{llll}
\hline & $\boldsymbol{\beta}$ & Sig. & $\boldsymbol{d}$ \\
\hline Overall intensity of interaction & .404 & .024 & .163 \\
- Speaking with NSs & .344 & .058 & \\
- Listening to conversations & .299 & .091 & \\
- Watching TV/videos & .288 & 1.56 & \\
\hline
\end{tabular}

Finally, a correlation between sociocultural adaptation and intensity of interaction revealed no significant association between the two constructs. This indicates that students seemed to improve their adaptation to the new setting independently of the amount of time they 
spend using the L2. If we compare results reported in Table 5 and Table 6, we can observe that the influence of intensity of interaction on pragmatic recognition was higher than the effect of sociocultural adaptation, as indicated in beta scores and effect sizes. Therefore, one can conclude that development of routine recognition was mainly determined by intensity of interaction and secondly by sociocultural adaptation.

\subsection{Qualitative findings: Learners' experiences}

To gain a more comprehensive understanding of the quantitative results reported above, answers by two of the informants, Tim and Jeff, in semi-structured interviews at the beginning and at the end of the semester were analyzed. Such qualitative analysis focused on 3 aspects: their awareness of pragmatic routines, their sociocultural adaptation experiences, and the amount and nature of their interactions in the L2. A descriptive analysis is displayed in Table 7, which includes quantitative findings on the participants' gains in routine recognition, in sociocultural adaptation - including behavioral and cognitive adaptation, and in intensity of interaction - encompassing speaking with NSs and listening to conversations.

Table 7. Gains in pragmatic competence, sociocultural adaptation and intensity of interaction by 2 informants.

\begin{tabular}{lllllll}
\hline & \multicolumn{2}{c}{ Tim } & \multicolumn{2}{c}{ Jeff } & \multicolumn{2}{c}{ AVERAGE } \\
\cline { 2 - 7 } & Score & $\%$ & Score & $\%$ & Score & $\%$ \\
\hline Routine recognition & 8 & 30.75 & 0 & 0 & 2.45 & 9.4 \\
\hline Sociocultural adaptation & 0.71 & 17.75 & 0.41 & 8.2 & 0.51 & 12.75 \\
- Behavioral adaptation & 0.89 & 22.25 & 0.27 & 5.4 & 0.47 & 11.75 \\
- Cognitive adaptation & 0.62 & 15.5 & 0.86 & 17.2 & 0.61 & 15.25 \\
\hline Intensity of interaction & 28.03 & 10.63 & -3.65 & -1.38 & 14.61 & 5.54 \\
- Speaking with NSs & 4.11 & 11.73 & -2.40 & -6.85 & 3.23 & 9.22 \\
- Listening to conversations & 5.34 & 15.26 & 0.03 & 0.08 & 3.32 & 9.49 \\
\hline
\end{tabular}


As one may observe in Table 7, Tim experienced gains in all of the aspects, while Jeff showed no gains in routine recognition, and a decrease in amount of interaction, but positive gains in sociocultural adaptation. In what follows, a detailed description of SA experiences of each participant is provided.

\subsubsection{Tim}

Tim's improvement in recognition of pragmatic routines was not only evident in the more appropriate assignment of prototypical meanings to each expression in the posttest version of the VKS, but also in his comments during the interviews. At the beginning of the semester, he explained that he was excited to learn daily expressions NSs use, because in Brazil he could only learn academic English. In the posttest interview, he indeed explained having learned some of these expressions, particularly at the recognition level. Tim reported the following with regards to learning pragmatic routines:

"a semester in the US is not enough to use all the knowledge you see and hear. I think next semester my speaking will improve because I will use what l've learnt this semester."

Looking at his answers in the routine recognition test, the routines where he experienced the largest gains were related to common situations of the SA context. These include my bad (frequent in NSs' speech, rather than in other L2 users' linguistic repertoire), do you think you could make it? (a common expression when being invited to an event by a friend), do you want to come to my place? (frequently heard when a friend invites you to his/her home), and help yourself (common expression situations involving a meal). We therefore hypothesize that exposure to the TL enhanced Tim's ability to recognize NSs' linguistic behavior. 
More particularly, his increased exposure to the TL culture was in terms of both intensity of interaction and sociocultural adaptation. An exploration of Tim's answers from pre- to posttest in the language contact survey revealed indeed that he substantially improved his amount of L2 use in "speaking in English outside of class with native or fluent speakers" and in "listening to conversations in English outside of class", while he slightly decreased his L2 use in watching TV/videos, speaking with instructors, and speaking with roommates. Regarding his answers in the SCAS, he improved his adaptation in most of the 29 scenarios, with the exception of the behavioral items "finding food that you enjoy", "dealing with the climate" and "going shopping."

From Tim's comments in the interviews, it seems that the two aspects - intensity of interaction and adaptation- improved over the semester thanks to social support from conational peers, and thanks to having a US girlfriend. He explains that without his "Brazilian family", he would have been too shy to go out and make friends with NSs. This could explain his improvement in the recognition of the routines "do you want to come to my place?" and "do you think you could make it?", which also correspond with sociocultural adaptation aspects such as making friends and going to social gatherings. Indeed, he met his US girlfriend at a party organized by the Brazilian students. According to Tim, having a US girlfriend has allowed him to make other US friends, with whom he often has dinner and plays videogames. Moreover, he was able to meet his girlfriends' family and friends during Thanksgiving break and, according to him, he was able to realize how different and interesting US culture is. Such a cultural exposure could explain Tim's improvement in his ability to recognize the pragmatic routine "my bad", which has a strong cultural boundness. All in all, Tim summarizes his first semester of SA as the best experience of his life, and attributes this success to making good Brazilian and US friends, and to learning aspects he did not expect he would have learnt, particularly in terms of cultural learning.

\subsubsection{Jeff}


The case of Jeff illustrates the stronger influence of intensity of interaction rather than sociocultural adaptation for the development of routine recognition. Out of all the participants originally interviewed, Jeff was the one that experienced the lowest gains in pragmatic awareness. As we may see in Table 7, on the one hand, his sociocultural adaptation increased through the semester, although overall gains and behavioral adaptation gains were below the average. On the other hand, his intensity of interaction decreased both in overall terms and in the specific situations.

Jeff's limited gains in the recognition of pragmatic routines were evident in his comments in the two interviews. At the beginning of the semester, he was not aware of having learned any expressions, and in the final interview he explained that although he felt he had learned to use some expressions, he was still not sure about the meaning of some expressions such as "potato heads" or "thanks for the heads up". In the posttest interview Jeff mentioned the following:

"Some expressions I know from the movies, like 'What's up?' but I learned.....ehm... for example 'potato heads'... I'm not really sure about the meaning but I think I know, and... 'thanks for the heads up'... like... when... I'm, I'm giving for these people some information but I really don't have to give so much, but I give them so they say thanks for the heads up."

His answers in the recognition test indeed illustrate such limited gains. For instance, while in the pretest he reported being familiar with the expression "I was wondering", in the posttest he reported knowing this expression but provided the non-plausible explanation "I am lost or without anywhere to go". Moreover, Jeff decreased his recognition of one routine - "my bad" (i.e. was familiar with it in the pretest but reported not knowing the expression in the posttest) - and increased his recognition of "do you have the time?" and "that works for me." Nevertheless, we learned from the quantitative analysis (c.f. section 4.1) that overall, participants decreased their recognition of "do you have the time?", probably because it does not correspond with a frequent scenario. To shed some light on Jeff's limited gains in the recognition of routines, we explored his answers to the language contact survey. 
As a matter of fact, Jeff's answers to the language contact survey revealed that he decreased the amount of exposure in most of the presented situations, except for in "listening to conversations" and "watching TV or videos". We hypothesize that the small gains in his recognition of some routines such as "do you have the time?" may be due to an increased amount of exposure to the TV rather than to authentic and daily exposure to situations that demanded interaction. Indeed, in the interviews, Jeff explained that although he consciously tried to interact with NSs, he was not able to increase his intensity of interaction. At the beginning of the semester, he complained that he could not find any opportunities to interact with US students, since he lived with Brazilian students and did not have opportunities for interaction in English in any of his classes. He tried to change his living situation, but his scholarship did not permit it. He also enrolled in a conversation partner program ${ }^{12}$, but he only met 3 times with a NS young woman. According to Jeff, she was not very helpful and they only maintained "the typical superficial conversations."

Towards the end of the semester, Jeff decided to join a club with the aim of making friends. He joined the "theatre club," and made a few good US friends there. Enrollment in this club, and observation of the norms of behavior of the L2 community there, was probably what explained Jeff's relatively successful sociocultural adaptation. According to Jeff, participation in the club did not allow him to interact much, as they only met for 2 hours a semester and they focused on performing rather than on interacting. Nevertheless, it allowed him to be more exposed to the US culture. As a result, his cognitive adaptation improved. This was reflected in comments in the posttest interview such as the following:

"Now I understand that American people are more similar to Brazilian people, so it's easier to be friends with them than with Chinese, for example."

Accordingly, an exploration of Jeff's answers to the SCAS at the beginning and at the end of the semester reveals a small increase in 12 of the 29 presented items, the largest gains being in the items "finding your way around" and "talking about yourself with others", aspects

\footnotetext{
12 Conversation partner is a service the university offers, in which a non-English-speaker international student exchanges conversations with an English-speaker student from the US with the aim of both students learning each other's' language and culture.
} 
which do not have much relationship with the ability to recognize recurrent language. Interestingly, he decreased his adaptation in 4 of the 29 items of the SCAS, three of which involve interaction with L2 users: "making friends", "going shopping" and "going to social gatherings", the fourth one being "finding food that you enjoy", fact which reflects his limited gains in amount of interaction.

In summary, a qualitative analysis of two case studies revealed individual trajectories of pragmatic learning that shed more light on the general patterns showed in the quantitative analysis; that is, the interplay among recognition of pragmatic routines, intensity of interaction and sociocultural adaptation. Regarding intensity of interaction, recognition of pragmatic routines such as "my bad" or "do you think you could make it?" was associated with increased amounts of time spent speaking with NSs (e.g. in the case of Tim, speaking with his girlfriend's family and friends) and listening to conversations (e.g. in the case of Jeff, listening in theater club). Regarding sociocultural adaptation, gains in the recognition of routines were related to both behavioral and cognitive adaptation, which seemed to be promoted not only by integration in the TL community (as in the case of Tim), but also by support from co-nationals (in the case of Jeff).

\section{Discussion}

The present study attempted to shed some light on the development of pragmatic competence in the SA context by addressing two research questions. The first one asked whether a semester of immersion in the US afforded gains in the recognition of pragmatic routines. The second one addressed whether the reported pragmatic gains were determined by learners' sociocultural adaptation to the SA context and by intensity of interaction with L2 speakers. 
Findings in relation to RQ1 indicated that a group of Brazilian students significantly improved their recognition of pragmatic routines during a SA program in the US. These results support the existent bulk of ILP studies reporting the advantage of the SA context for learning pragmatic competence (see Xiao 2015a for a review), and in particular for the learning of pragmatic routines (Barron, 2003, this issue; Taguchi et al., 2013; Alcón-Soler \& SánchezHernández, 2017; Osuka, 2017). The innovation of this study lies in the focus on the recognition of pragmatic routines. Despite the acknowledgement that recognition and production of routines represent different abilities (Bardovi-Harlig, 2008, 2009; BardoviHarlig \& Bastos, 2011; Taguchi \& Roever, 2017), and that the first months of immersion in the SA context particularly afford gains in recognition (Alcón-Soler \& Sánchez-Hernández, 2017), longitudinal ILP works have mainly focused on production ${ }^{13}$. Findings from this study revealed that, over 4 months of immersion, students learned to assign plausible meanings to pragmatic routines they did not understand at the beginning of the sojourn. For example, they initially understood "do you think you could make it?" as a request for the ability to perform a task, and at the end of the semester participants had learned that it is an invitation to an event. This finding is in line with previous investigations that have pointed out that L2 students learn to assign plausible meanings to routines through exposure to the SA context (Kecskes, 2000; Bardovi-Harlig, 2014).

Moreover, results in relation to RQ1 corroborate previous investigations that have highlighted the variable nature of L2 pragmatic development (Félix-Bradefer, 2004; Taguchi, 2008). In this study, the target pragmatic routines presented different degrees of difficulty. Students showed higher gains in the recognition of routines such as "that works for me" and "do you want to come to my place?", while they showed limited gains in other routines such as "help yourself" and "thanks for coming". Drawing from previous cross-sectional studies pointing out the important role of exposure to the situations where routines are used

${ }^{13}$ Exception include Bardovi-Harlig and Dörnyei (1998) and Schauer (2006), which focused on pragmatic awareness. 
(Roever, 2012; Taguchi et al. 2013), we may hypothesize that students did not have enough exposure to the given situations in some of the routines. A further explanation could be that students were already familiar with the routines at the beginning of the semester, and thus did not show any change.

Regarding RQ2, research findings revealed that gains in the recognition of routines were determined mainly by intensity of interaction and secondly by sociocultural adaptation. Considering that the meaning of pragmatic routines is not embedded in the pragmalinguistic element itself, but it is acquired from the context (Kesckses, 2000), for a successful recognition of routines learners need to acquire the sociopragmatic knowledge necessary to discern the correct significance. The current study revealed that SA participants acquire sociopragmatic knowledge through sociocultural adaptation and, more effectively, through amount and variety of interactions with L2 users. The interplay among sociocultural adaptation, intensity of interaction and pragmatic development reported in this study echoes the findings by Taguchi et al. (2016). In both investigations, intensity of interaction was the main predictor of pragmatic gains, and sociocultural adaptation was the second one. Differences between the present and Taguchi et al.'s (2016) study are in terms of the target pragmatic feature and on the context. While Taguchi et al. (2016) focused on speech act production in a Chinese SA context, this study addresses the recognition of routines in the US setting. In addition to this, Taguchi et al. (2016) found that intensity of interaction and adaptation were correlated; that is, adaptation influenced interaction, while in the present study the two constructs were unrelated.

Regarding sociocultural adaptation, findings on its influence on L2 pragmatic development represent a notable contribution to the ILP field, since the role of adaptation experiences has been disregarded to date. The present findings showed that both behavioral and cognitive adaptation are important for the development of routine recognition, therefore supporting 
Schumann's (1978) claim that the degree to which an individual acculturates will determine his/her learning of an L2. On the one hand, it seems that L2 learners need to develop their social skills to interact with members of the TL community and to handle daily situations. On the other hand, they also need to improve their understanding of cross-cultural differences and of US sociocultural values. The small number of previous studies addressing the association between sociocultural adaptation and pragmatic development has revealed mixed findings. This study is in line with previous investigations reporting a significant influence (Schmidt, 1983; Dörnyei et al., 2004; Sánchez-Hernández, 2018a; forthcoming 2018b), while it is inconsistent with works that have observed a non-significant (Shively \& Cohen, 2008) or partial influence (Taguchi, 2014). Moreover, the study adds to the existent picture the finding that sociocultural adaptation and subsequent L2 pragmatic awareness are enhanced not only by contact with NSs but also by support from co-nationals.

As for intensity of interaction, the present findings support previous investigations that have reported that amount and nature of interaction with L2 users affects pragmatic development in general (Taguchi 2008; Bella, 2011, 2012; Félix-Brasdefer, 2013) and pragmatic routines in particular (Bardovi-Harlig \& Bastos, 2011; Taguchi et al., 2013). Therefore, it supports previous studies based on the language socialization theory (Ochs, 1996; Shively, 2011), which suggest that interaction in everyday practices is linked with $\mathrm{L} 2$ pragmatic learning. More particularly, our study revealed that recognition of routines was influenced by overall intensity of interaction, and more particularly by an increase of interaction in 2 situations, namely speaking with NSs (e.g. Tim with his girlfriend's family and friends) and listening to conversations enhanced (e.g. Jeff in theater club). Moreover, findings provide new insights on the relationship between intensity and pragmatic development from a longitudinal perspective. A small bulk of studies (Matsumura, 2003; Shively \& Cohen, 2008; Taguchi et al., 2016) has analyzed intensity of interaction and pragmatic competence over time. This is an important aspect to investigate since SA participants, as shown in this study, are likely to change both their amount of interaction with L2 users and the type of interactions. 
In addition, findings in relation to RQ2 - that is, the positive effect of intensity of interaction and sociocultural adaptation on L2 pragmatic development - provide empirical evidence of recent theoretical approaches that view L2 pragmatic learning over time as a complex and dynamic process (Taguchi, 2012). The use of a mixed-methods approach in this study has allowed us to observe both general patterns of pragmatic development and individual trajectories of pragmatic learning. On the one hand, a quantitative analysis has revealed an overall improvement on the participants' ability to recognize pragmatic routines. This improvement was however determined by the interplay among variables related to the context, the culture and the L2 learners' individual differences. On the other hand, a qualitative analysis has revealed individual developmental paths that indicate that pragmatic learning over time is not a linear process. This study has reported 2 case studies, one of a learner who experienced pragmatic gains, and one of a learner who did not show an improvement in his ability to recognize routines.

Ultimately, findings from this study contribute to our understanding of how students acquire knowlege of pragmatic routines over time during a SA program. Alcón-Soler and SánchezHernández (2017) reported that the first semester of immersion particularly enhanced the recognition of routines. Barron (2003), Taguchi et al. (2013), and Osuka (2017) revealed that gains in production of routines are determined by opportunities of interaction and exposure to input, while the present study adds up that recognition of routines is mainly affected by intensity of interaction, and secondly by sociocultural adaptation. Our findings also suggest that unlike other pragmatic features, the acquisition of pragmatic routines requires a higher level of integration in the TL community, and therefore the SA context is optimal for routine learning (Taguchi et al., 2013).

\section{Conclusion}


Findings from the present study have revealed that a semester-long SA program enhances the recognition of pragmatic routines, and that the reported pragmatic gains are determined mainly by intensity of interaction and secondly by sociocultural adaptation. In doing so, the study bridges the gap between intercultural and pragmatic competences, addressing the current call to explore the interdependence of the two abilities as a result of the increased intercultural contact that comes with globalization (Sykes, 2017; Taguchi et al., 2016; Taguchi \& Roever, 2017). More particularly, this study has showed that the acquisition of pragmatic and intercultural competences are interrelated processes that take place during interaction with different L2 users in recurrent situations of the SA context.

Like all research, the study has a number of limitations, which at the same time provide directions for future research. In first place, we used quantitative instruments to measure learners' self-reported recognition of pragmatic routines, sociocultural adaptation, and intensity of interaction. We acknowledge that self-report measures have the disadvantage of not being a hundred per cent valid for the establishment of generalisations, as participants may not be truthful or may exaggerate their answers. However, this limitation was overcome by including interviews to further understand the quantitative results. Moreover, this longitudinal study did not involve a delayed posttest, and therefore only considered whether students experienced gains from the beginning to the end of the first semester of immersion. Future works should considered administration of a delayed posttest to analyze whether pragmatic knowledge is sustained upon return to the home country or over one year of immersion abroad. In this sense, the language contact survey could additionally be administered also in-between pre- and posttest, as Fernández and Tapia (2016) suggest, given the fact that contact can change over the course of the stay abroad and not just from beginning to end, but in-between. In addition to this, the present analysis focused on Brazilian students, and therefore findings may not be generalized to the whole population of student mobility. Acknowledging the fact that knowledge of pragmatic routines is determined by students' cultural background (Sánchez-Hernández, 2018a; Sánchez-Hernández \& 
Alcón-Soler, forthcoming 2018b), further studies are needed with different SA learner samples.

Finally, the present study brings about important implications for instructors, researchers and SA coordinators. It highlights the need to maximize students' SA experiences and provides information about some factors that could facilitate pragmatic learning in SA contexts. Moreover, findings reveal that the development of pragmatic competence in the SA context is not a straightforward matter. Mere exposure to the context is not enough, and SA participants need to take the opportunities the context offers for interaction and for sociocultural learning.

\section{Acknowledgements}

\section{References}

Alcón-Soler, Eva, 2015. Pragmatic learning and study abroad: Effects of instruction and length of stay. System $48,62-74$.

Alcón-Soler, Eva, 2017. Pragmatic Development During Study Abroad: An Analysis of Spanish Teenagers' Request Strategies in English Emails. Annual Review of Applied Linguistics 37, 77-92.

Alcón-Soler, Eva, Sánchez-Hernández, Ariadna, 2017. Learning pragmatic routines during study abroad: a focus on proficiency and type of routine. Atlantis 39(2), 191-210.

Al-Gahtani, Saad, Roever, Carsten, 2012. Proficiency and sequential organization of L2 requests. Applied Linguistics 33(1), 42-65.

Bardovi-Harlig, Kathleen, 2008. Recognition and production of formulas in L2 pragmatics. In:

Han, Z. H. (Ed.), Understanding second language process. Clevedon, UK: Multilingual Matters, pp. 205-222. 
Bardovi-Harlig, Kathleen 2009. Conventional expressions as a pragmalinguistics resource: Recognition and production of conventional expressions in L2 pragmatics. Language Learning 49(4), 755-95.

Bardovi-Harlig, Kathleen 2014. Awareness of meaning of conventional expressions in second language pragmatics. Language Awareness 23: 41-56.

Bardovi-Harlig, Kathleen; Bastos, Maria-Thereza, 2011. Proficiency, length of stay, and intensity of interaction, and the acquisition of conventional expressions in L2 pragmatics. Intercultural Pragmatics 8(3), 347-384.

Bardovi-Harlig, Kathleen, Dörnyei, Zahran, 1998. Do language learners recognize pragmatic violations? Pragmatic vs. grammatical awareness in instructed L2 learning. TESOL Quarterly 32, 233-259.

Barron, Anne, 2003. Acquisition in interlanguage pragmatics: learning how to do things with words in a study abroad context. Amsterdam: Benjamins.

Barron, Anne, this issue. Pragmatic routines in learner apologies: Studying development during a sojourn abroad.

Bataller, Rebeca, 2010. Making a Request for a Service in Spanish: Pragmatic Development in the Study Abroad Setting. Foreign Language Annals 43(1), 160-175.

Bella, Spyridoula, 2011. Mitigation and politeness in Greek invitation refusals: Effects of length of residence in the target community and intensity of interaction on non-native speakers' performance. Journal of Pragmatics 43, 1718-1740.

Bella, Spyridoula, 2012. Pragmatic awareness in a second language setting: the case of L2 learners of Greek. Multilingua 31(1), 1-33.

Bennett, Milton J., 1993. Towards ethnorelativism: A developmental model of intercultural sensitivity. In: Paige, R. M. (Ed.), Education for the intercultural experience. Yarmouth, ME: Intercultural Press, pp. 21-71.

Berry, John, 1980. Acculturation as varieties of Adaptation. In: Amado M. Padilla (Ed.), Acculturation: Theory, Models and Some New Findings. Boulder, CO: Westview Press, $9-25$. 
Byram, Michael, 2012. Conceptualizing intercultural (communicative) competence and intercultural citizenship. In: Jackson, J. (Ed.), The Routledge handbook of language and intercultural communication. New York: Routledge/Taylor \& Francis, pp. 85-98.

Chiu, Chi-Yue, Lonner, Walter J., Matsumoto, David, Ward, Colleen, 2013. Cross-cultural competence theory, research, and application. Journal of Cross-Cultural Psychology 44: 843-848.

Cohen, Andrew, Shively, Rachel, 2007. Acquisition of requests and apologies in Spanish and French: Impact of study abroad and strategy-building intervention. Modern Language Journal 91, 189-212.

Davis, John, 2007. Resistance to L2 pragmatics in the Australian ESL context. Language Learning 57, 611-649.

Dechert, Hans, 1983. How a story is done in a second language. In: Faech, C., Kasper, G. (Eds.), Strategies in interlanguage communication. London, UK: Longman, pp. 175195.

Dewey, Dan, 2017. Measuring social interaction during study abroad: Quantitative methods and challenges. System 71, 49-59.

Dörnyei, Zoltán, Durow, Valerie, Zahran, Kawla, 2004. Individual differences and their effects on formulaic secquence acquisition. In: Schmitt, N. (Ed.), Formulaic sequences: Acquisition, processing and use. Amsterdam: Benjamins, pp. 87-106.

Eslami, Zohreh, Jin Ahn, Soo, 2014. Motivation, amount of interaction, length of residence, and ESL learners' pragmatic competence. Applied Research on English Language 3(1), 9-28.

Fantini, Alvino, 2006. Exploring and Assessing Intercultural Competence. Retrieved April 16th from http://digitalcollections.sit.edu/worldlearning_publications/1/

Félix-Brasdéfer, César, 2004. Interlanguage refusals: Linguistic politeness and length of residence in the target community. Language Learning 54(4), 587-653.

Félix-Brasdefer, César, 2013. Refusing in L2 Spanish: the effects of the context of learning during a short-term study abroad program. In: Martí-Arnándiz, O., Salazar-Campillo, P. 
(Eds.), Refusals in instructional contexts and beyond. Amsterdam: Rodopi, pp. 147173.

Fernández, Julieta, Tapia, Anna, 2016. An appraisal of the Language Contact Profile as a tool to research local engagement in study abroad. Study Abroad Research in Second Language Acquisition and International Education 1, 248-276.

Freed, Barbara, 1995. What makes us think that students who study abroad become fluent? In: Freed, B. (Ed.), Second language acquisition in a study abroad context. Philadelphia: John Benjamins, pp. 123-148.

Freed, Barbara, Dewey, Dan, Segalowitz, Norman, Halter, Randall, 2004. The language contact profile. Studies in Second Language Acquisition 26, 349-356.

Hassall, T. (2006). Learning to take leave in social conversations: A diary study. In M. A. DuFon \& E. Churchill (Ed.), Language learners in study abroad contexts. Clevedon, UK: Multilingual Matters, pp. 31-58.

lino, Masakazu, 1996. 'Excellent foreigner!': Gaijinization of Japanese language and culture in contact situations: An ethnographic study of dinner table conversations between Japanese host families and American students . Unpublished doctoral thesis, University of Pennsylvania, Philadelphia.

Kecskes, Istvan, 2000. A cognitive-pragmatic approach to situation-bound utterances. Journal of Pragmatics 32 (6), 605-625.

Kecskes, Istvan, 2010. Situation-bound utterances as pragmatic acts. Journal of Pragmatics 42(11), 2889-2897.

Kelley, Colleen, Meyers, Judith, 1995. Cross-cultural adaptability inventory manual. Arlington, VA: Vangent.

Kinginger, Celeste, 2008. Language learning in study abroad: Case studies of Americans in France. Modern Language Journal 92(1), 1-124.

Leung, Kwok, Ang, Soon, Tan, Mei Ling, 2014. Intercultural competence. Annual Review of Organizational Psychology and Organizational Behavior 1, 489-519 
Masgoret, Anne-Marie, Ward, Coleen, 2006. Culture learning approach to acculturation. In: D. L. Sam, J. W. Berry (Eds.), The Cambridge handbook of acculturation psychology. New York, NY, US: Cambridge University Press, 58-77.

Matsumura, Shoichi, 2003. Modeling the relationship among interlanguage pragmatic development, L2 proficiency, and exposure to L2. Applied Linguistics 24, 465-491.

Ochs, Elinor, 1996. Linguistic resources for socializing humanity. In: Gumperz, J.J., Levinson, S.C. (Eds.), Rethinking Linguistic Relativity. Cambridge, Cambridge, pp. 407-437.

Ochs, Elinor, Schieffelin, Bambi B., 2008. Language socialization: an historical overview. In: Duff, P.A., Hornberger, N.H. (Eds.), Encyclopedia of Language and Education, Volume 8: Language Socialization. Springer, New York, pp. 3-15.

Osuka, Naoko, 2017. Development of pragmatic routines by Japanese learners in a study abroad context. In: Kecskes, I., Assimakopoulos, S. (Eds.), Current Issues in Intercultural Pragmatics. Benjamins: Amsterdam/ NY, pp. 275-296.

Rafieyan, Vahid, Behnammohammadian, Nazanin, Orang, Maryam, 2015. Relationship between acculturation attitudes and pragmatic comprehension. Journal of Language Teaching and Research 6, 504-512.

Ren, Wei, 2015. L2 Pragmatic Development in Study Abroad Contexts. Bern: Lang.

Roever, Carsten, 2005. Testing ESL Pragmatics: Development and validation of a webbased assessment battery. Berlin: Peter Lang.

Roever, Carsten, 2012. What learners get for free (and when): Learning of routine formulae in ESL and EFL environments. English Language Teaching Journal 66(1), 10-21.

Roever, Carsten, Wang, Stanley, Brophy, Stephanie, 2014. Learner background factors and learning of second language pragmatics. IRAL 52(4), 377-401.

Safont-Jordà, Maria Pilar, Alcón-Soler, Eva, 2018. Mixed method approaches in investigating pragmatic learning. Special issue. System.

Sánchez-Hernández, Ariadna, 2018a. A mixed-methods study of the impact of sociocultural adaptation on development of pragmatic production. System 75. 93-105. 
Sánchez-Hernández, Ariadna, Forthcoming, 2018b. Acculturation and pragmatic learning: International students in the US. In: Pérez-Vidal, C., López-Serrano, S., Ament, J., Thomas-Wilhelm, D. (Eds.), Learning effects: Study abroad, formal instruction and international immersion classrooms. EUROSLA Series.

Sánchez-Hernández, Ariadna, Alcón-Soler, Eva, Forthcoming 2018. The role of individual differences on recognition and production of pragmatic routines. In: Salazar, P., Codina, V. (Eds.), Investigating the learning of pragmatics across ages and contexts. Brill.

Schauer, Gila, 2006. Pragmatic awareness in ESL and EFL contexts: contrast and development. Language Learning 56, 269-318.

Schauer, Gila, 2009. Interlanguage pragmatic development: The study abroad context. London, UK: Continuum.

Schmidt, Richard W., 1983. Interaction acculturation, and the acquisition of communicative competence: A case study of an adult. In: Wolfeson, N., Judd, E. (Eds.), Sociolinguistics and language acquisition. Rowley, MA: Newbury House, pp. 137-174.

Schumann, John, 1978. The Pidginization process: a model for second language acquisition. Rowley, MA: Newbury House.

Shively, Rachel, 2011. L2 pragmatic development in study abroad: A longitudinal study of Spanish service encounters. Journal of Pragmatics 43, 1818-1835.

Shively, Rachel, Cohen, Andrew, 2008. Development of Spanish requests and apologies during study abroad. Ikala, revista de lenguaje y cultura 13(20), 57-108.

Siegal, Meryl, 1995. Individual differences and study abroad: Women learning Japanese in Japan. In: B. Freed (Ed.), Second language acquisition in the study abroad context. Amsterdam, Netherlands: John Benjamins, 225-245

Sykes, Julie, 2017. Technologies for teaching and learning intercultural competence and interlanguage pragmatics. In: Sauro, S., Chapelle, C. (Eds.). The Handbook of Technology and Second Language Teaching and Learning. Hoboken, NJ, USA: John Wiley \& Sons, pp. 118-133. 
Taguchi, Naoko, 2008. Cognition, language contact, and development of pragmatic comprehension in a study-abroad context. Language Learning 58, 33-71.

Taguchi, Naoko, 2011. The Effect of L2 Proficiency and Study-Abroad Experience on Pragmatic Comprehension. Language Learning 61(3), 904-939.

Taguchi, Naoko, 2012. Context, individual differences and pragmatic competence. Bristol, UK: Multilingual Matters.

Taguchi, Naoko, 2013. Production of routines in L2 English: Effect of proficiency and studyabroad experience. System 41, 109-121.

Taguchi, Naoko, 2015. Cross-cultural adaptability and development of speech act production in study abroad. International Journal of Applied Linguistics 25(3), 343-365.

Taguchi, Naoko, 2016. Contexts and pragmatics learning: Problems and opportunities of the study abroad research. Language Teaching 1, 1-14.

Taguchi, Naoko, Li, Shuai, Xiao, Feng, 2013. Production of formulaic expressions in L2 Chinese: A developmental investigation in a study abroad context. Chinese as a Second Language Research Journal 2(1), 23-58.

Taguchi, Naoko, Xiao, Feng, Li, Shuai, 2016. Effects of intercultural competence and social contact on speech act production in a Chinese study abroad context. The Modern Language Journal 100(4), 1-22.

Taguchi, Naoko, Roever, Carsten, 2017. Second language pragmatics. Oxford: Oxford University Press.

Tajeddin, Zia, Alemi, Minoo, Pashmforoosh, Roya, 2017. Acquisition of Pragmatic Routines by Learners of L2 English: Investigating Common Errors and Sources of Pragmatic Fossilization. The Electronic Journal for English as a Second Language 21(2), 1-21.

Vande Berg, Michael, Paige, Michael, Lou, Kris (eds.) (2012). Student learning abroad: What our students are learning, what they're not, and what we can do about it. Sterling, VA: Stylus.

Ward, Colleen, Kennedy, Antony, 1999. The measurement of sociocultural adaptation. International Journal of Intercultural Relations 23, 659-677. 
Ward, Colleen, Bochner, Stephen, Furnham, Adrian, 2001. The Psychology of Culture Shock 2nd Ed. London: Routledge.

Weinert, Regina, 1995. The role of formulaic language in second language acquisition: a review. Applied Linguistics 16(2), 180-205.

Wesche, Marjorie, Paribakht, T. Sima, 1996. Assessing second language vocabulary knowledge: Depth vs. breadth. Canadian Modern Language Review 53, 13-40.

Wilkinson, Sharon, 1998. Study abroad from the participants' perspective: A challenge to common beliefs. Foreign Language Annals 31, 23-39.

Wilkinson, Jane, 2012. The intercultural speaker and the acquisition of intercultural global competence. In: Jackson, J. (Ed.), Routledge Handbook of language and intercultural communication. Florence, KY: Routledge, pp. 296-309.

Wray, Alison, 2000. Formulaic sequences in second language teaching: Principles and practice. Applied Linguistics 21(4), 463-489.

Xiao, Feng, 2015a. Adult second language learners' pragmatic development in the studyabroad context: A review. Frontiers: the Interdisciplinary Journal of Study Abroad 25, 132-149.

Xiao, Feng, 2015b. Proficiency effect on L2 pragmatic competence. Studies in Second Language Learning and Teaching 5(4), 557-581.

\section{Appendix. Language Contact Survey}

- Please respond to the following questions:

Which situation best describes your living arrangements in the United States this semester?

a. I live in the home of an English-speaking family.

1) List the members of the family (e.g. father, mother):

2) Do they speak English? Yes / No

b. I live in the student dormitory.

1) I have a private room. 
2) I have a roommate who is a native or fluent English speaker.

3) I live with others who are NOT native or fluent English speakers.

c. I live alone in a room or apartment.

d. I live in a room or apartment with native or fluent English speakers.

e. I live in a room or an apartment with others who are NOT native or fluent English speakers.

f. Other. Please specify.

- Please respond to the questions below by circling the appropriate numbers.

1. On average, how much time do you spend speaking in English outside of class with native or fluent speakers during this semester?

$\begin{array}{llllllllll}\text { Typically, how many days per week? } & 0 & 1 & 2 & 3 & 4 & 5 & 6 & 7\end{array}$

On those days, how many hours per day? $\quad \begin{array}{llllll}0-1 & 1-2 & 2-3 & 3-4 & 4-5 & \text { more than } 5\end{array}$

2. On average, how much time do you spend speaking in English to your instructor?

$\begin{array}{llllllllll}\text { Typically, how many days per week? } & 0 & 1 & 2 & 3 & 4 & 5 & 6 & 7\end{array}$

On those days, how many hours per day? $\begin{array}{llllll}0-1 & 1-2 & 2-3 & 3-4 & 4-5 & \text { more than } 5\end{array}$

3. On average, how much time do you spend speaking in English to your classmates?

$\begin{array}{lllllllllll}\text { Typically, how many days per week? } & 0 & 1 & 2 & 3 & 4 & 5 & 6 & 7\end{array}$

$\begin{array}{lllllll}\text { On those days, how many hours per day? } & 0-1 & 1-2 & 2-3 & 3-4 & 4-5 & \text { more than } 5\end{array}$

4. On average, how much time do you spend speaking in English to strangers?

$\begin{array}{llllllllll}\text { Typically, how many days per week? } & 0 & 1 & 2 & 3 & 4 & 5 & 6 & 7\end{array}$

On those days, how many hours per day? $\quad \begin{array}{llllll}0-1 & 1-2 & 2-3 & 3-4 & 4-5 & \text { more than } 5\end{array}$

5. On average, how much time do you spend speaking in English to your host family, roommate, or friends who are native or fluent speakers?

$\begin{array}{lllllllllll}\text { Typically, how many days per week? } & 0 & 1 & 2 & 3 & 4 & 5 & 6 & 7\end{array}$

On those days, how many hours per day? $\begin{array}{lllllll}0-1 & 1-2 & 2-3 & 3-4 & 4-5 & \text { more than } 5\end{array}$

6. On average, how much time do you spend speaking in English outside the classroom with service personnel?

$\begin{array}{llllllllll}\text { Typically, how many days per week? } & 0 & 1 & 2 & 3 & 4 & 5 & 6 & 7\end{array}$ 
On those days, how many hours per day? $\begin{array}{lllllll}0-1 & 1-2 & 2-3 & 3-4 & 4-5 & \text { more than } 5\end{array}$

7. How much time do you spend listening in English outside the class?

$\begin{array}{llllllllll}\text { Typically, how many days per week? } & 0 & 1 & 2 & 3 & 4 & 5 & 6 & 7\end{array}$

$\begin{array}{lllllll}\text { On those days, how many hours per day? } & 0-1 & 1-2 & 2-3 & 3-4 & 4-5 & \text { more than } 5\end{array}$

8. How much time do you spend watching movies, TV, or videos in English outside of class?

$\begin{array}{llllllllll}\text { Typically, how many days per week? } & 0 & 1 & 2 & 3 & 4 & 5 & 6 & 7\end{array}$

On those days, how many hours per day? $\begin{array}{llllll}0-1 & 1-2 & 2-3 & 3-4 & 4-5 & \text { more than } 5\end{array}$ 